\title{
ESTUDO DA FERMENTAÇÃO ALCOÓLICA DE SOLUÇÕES DILUÍDAS DE DIFERENTES AÇUCARES UTILIZANDO MICROCALORIMETRIA DE FLUXO
}

Pedro L. O. Volpe

Instituto de Química - UNICAMP - 13083-970 - Campinas - SP

Recebido em 8/4/96; aceito em 18/12/96

\begin{abstract}
STUDY OF THE ALCOHOLIC FERMENTATION OF SUGARS DILUTED SOLUTIONS THROUGH FLOW MICROCALORIMETRY. The present study shows that with liquid nitrogen stored inocula of Saccharomyces cerevisiae, and standardized experimental procedure, flow microcalorimetry can be a valuable tool for monitoring in real time the alcoholic fermentation processes on line. The avaliation of cultural conditions contained different carbon sources for alcohol fermentation (sucrose, glucose, fructose, manose, maltose, galactose, molasses, honey and sugar cane) and their effects on the heat output recording is discussed. Some examples of diauxic growth is given, where the microcalorimeters serves to detect the temporal order of succession of alternating metabolic pathways.
\end{abstract}

Keywords: flow microcalorimetry; heat output; fermentation; Saccharomyces cerevisiae.

\section{INTRODUÇÃO}

A liberação de calor é uma propriedade geral do crescimento de microrganismos independentemente da natureza da fonte de carbono, ou se o processo é aeróbico ou anaeróbico. É surpreendente que o primeiro experimento calorimétrico com microrganismos relacionado com fermentação que se tem notícia, foi desenvolvido numa dorna de cervejaria por Dubrunfaut ${ }^{1} \mathrm{em}$ 1856 e talvez Lavoisier somente tenha malogrado em medir o calor liberado para o meio durante o crescimento de leveduras, em seus intensivos estudos do calor e da fermentação, porque ele estava limitado a $0^{\circ} \mathrm{C}$ pelo seu calorímetro de gelo ${ }^{2}$. O experimento de Dubrunfaut poderia ser chamado hoje de "calorimetria dinâmica" e incentivou Rubner ${ }^{3-6}$, no início do século, a começar as primeiras medidas calorimétricas verdadeiras, quantificando a produção de calor durante a fermentação e o crescimento das leveduras. Muitas medidas calorimétricas da energia do metabolismo subsequentes ao trabalho de Rubner não foram calorimétricas no sensu strictu porque não mediam diretamente o calor produzido durante o crescimento.

A fermentação alcoólica (catabolismo anaeróbico) fornece energia na forma de ATP ou outros compostos de transferência de energia para a biossíntese do material celular e produção do etanol. Estas reações catabólicas acontecem com uma grande diminuição na energia livre, a qual junto com a subsequente hidrólise do ATP durante as reações de biossíntese, transporte e manutenção, resulta na produção de calor. Um balanço energético simplificado para a equação do catabolismo anaeróbico da glicose pela $S$. cerevisiae, pode ser descrito da seguinte forma:

\section{GLICOSE $\rightarrow 2 \mathrm{CO}_{2}+2$ ETANOL; DG $=-175 \mathrm{~kJ} / \mathrm{mol}$ de glicose}

O detalhamento desta reação está representada na figura 1, com os respectivos valores de energia livre para cada etapa.

Durante os anos 60, Calvet Prat e Skinner ${ }^{7}$ deram importante impulso à microcalorimetria estudando a termogenese de sistemas vivos. A importância do calor como uma maneira de monitorar e possivelmente controlar processos fermentativos, é refletida pelo aumento crescente de trabalho publicados nesta área ${ }^{8-20}$.

Nos anos 80, devido à utilização das termopilhas ${ }^{21}$ (Peltier ou componente termoeletrônico desenvolvido durante a corrida espacial) na construção de calorímetros, tornou-se possível experimentos de acompanhamento de processos de natureza biológica.
Beezer $^{22}$ e Wadsö ${ }^{23}$ contribuíram fundamentalmente no estabelecimento da área conhecida hoje como microcalorimetria biológica.

Os dados da literatura têm mostrado que a velocidade de produção de calor em fermentações pode ser útil de diversas maneiras tanto na pesquisa acadêmica como em aplicações industriais. As correlações gerais entre produção de calor e vários outros parâmetros sugerem que a velocidade de produção de calor pode ser usada como uma medida para monitorar em tempo real fermentações, consumo de oxigênio ou a velocidade de produção de $\mathrm{CO}_{2}$.

Apesar dos esforços para se introduzir métodos instrumentais modernos, até o momento existem pouquíssimos métodos "on line" para o monitoramento de processo fermentativos em tempo real. Os métodos de controle dos processos analíticos de laboratório "off line" ainda exercem um papel importante na monitoração da fermentação para finalidades industriais e de pesquisa.

Entre as desvantagens destes métodos, a maior é a demora entre a retirada das amostras e obtenção dos resultados analíticos, que deve ser feita durante o processo fermentativo. Entretanto, quando métodos analíticos "off line" são usados, geralmente não é possível utilizar as vantagens dos micro-computadores no processo de controle. O controle analítico "on line" de processos de fermentação geralmente abrange medidas de quantidades físicas e químicas. Por várias razões, os indicadores da população de microrganismos e outros parâmetros ligados ao crescimento de células (ex. produção de calor) são indispensáveis para o controle dos processos de fermentação.

Como já descrito previamente ${ }^{24-25}$ a microcalorimetria de fluxo constitui uma técnica analítica não específica para caracterizar processos de crescimento e morte de microrganismos.

Por meio desta técnica, o calor produzido por todos os eventos metabólicos que acontecem no meio de cultura, podem ser registrados em tempo real sem perturbar o processo. Se necessário for, amostras podem também ser retiradas periodicamente para a análise do consumo do substrato ou aparecimento dos produtos sem prejudicar o experimento. Desta maneira, a curva potência-tempo dq/dt ( $\mu$ Watts) x tempo(horas) ou termograma ${ }^{26}$, monitora in situ e em tempo real o processo fermentativo, não requerendo meio transparente.

A figura 2 mostra um esquema de um termograma para um processo fermentativo em condições anaeróbicas em meio definido e com baixa concentração de fonte de carbono. Neste 

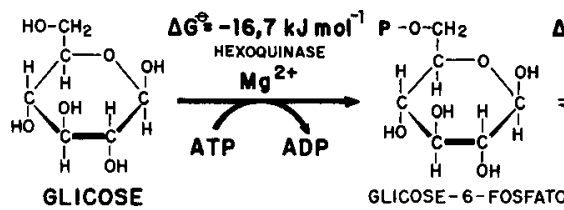

$\Delta B^{\theta}=+1,7 \mathrm{~kJ} \mathrm{~mol}^{-1}$

ISOMERASE

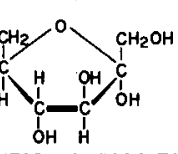

FRUTOSE-6-FOSFATO

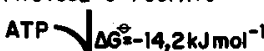

FOSFOFRUTOQUIMASE

ADP $\mathrm{Mg}^{2+}$

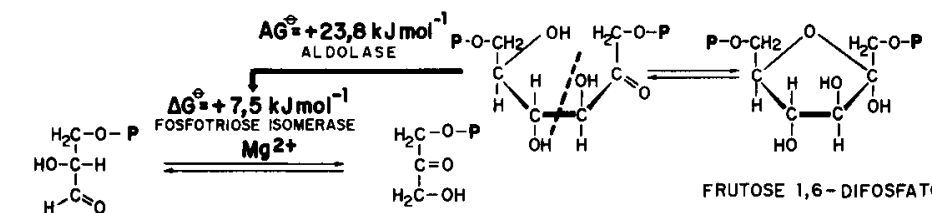

3 FOSFATO DO ALOEIDO FOSFODIHIDROXICETONA

$2 \mathrm{NAO}+\mathrm{P} \| 2 \times\left(\Delta \mathrm{G}^{\circ} \rightarrow 6,3 \mathrm{kJ \textrm {mol } ^ { - 1 } )}\right.$ TRIOSE FOSFATO

$2 \mathrm{NADH}^{+} \mathrm{H}^{+} \quad \mathrm{Zn}^{2+} \quad 2 \times\left(\Delta G^{\ominus}=+4,6 \mathrm{kJmol}^{-1}\right.$
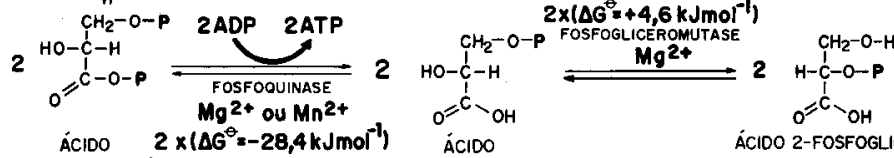
ÁCIOO 2-FOSFOGLICÉRICO
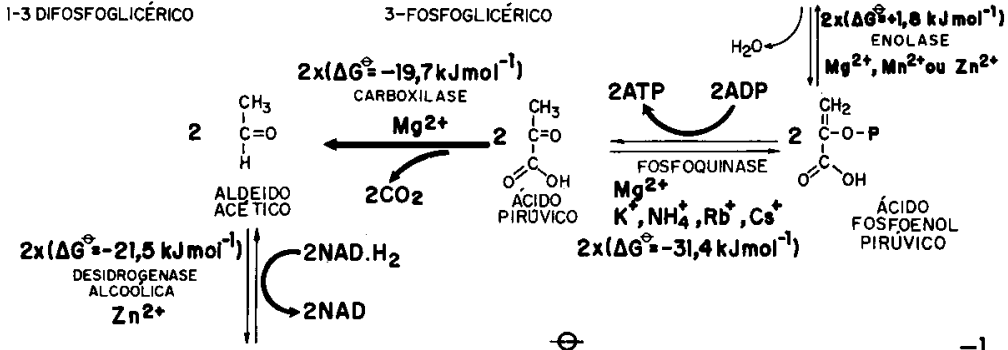

$2 \times\left(\Delta G^{\ominus}=-31,4 \mathrm{kJmal}^{-1}\right)$

PIRUVICO

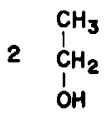

$\Delta G_{\text {processo }}^{\ominus}=-175 \mathrm{kJmol}$

ETANOL.

Figura 1. Valores da variação de energia livre para cada etapa do catabolismo anaeróbico da glicose pela S. cerevisiae.

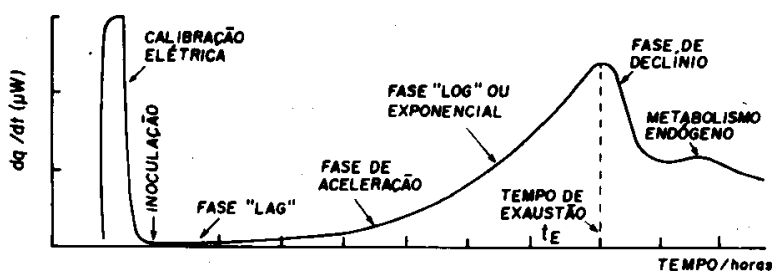

Figura 2. Termograma esquemático para um processo fermentativo em condições anaeróbicas.

termograma estão indicadas a calibração elétrica, o ponto de inoculação e as várias fases do processo fermentativo em termos de produção de calor. Durante a fase "lag" ou de adaptação, não ocorre produção de calor significativa. Durante este tempo nenhum crescimento ocorre, desde que as células nesta fase estão ocupadas em estabelecer o estado enzimático necessário para o catabolismo $^{11}$. A produção de calor inicia na fase de aceleração decorrente do crescimento dos microrganismos sem obedecer uma lei exponencial. Durante a fase "log" a produção de calor e consequentemente a produção de etanol, é exponencialmente dependente do tempo. No tempo de exaustão, a baixa concentração de fonte de carbono ou a alta concentração de etanol limita a velocidade de crescimento. Após o tempo de exaustão inicia-se a fase de declínio com um tempo de duração de aproximadamente 1 hora onde o número de células que morrem torna-se progressivamente superior ao das que surgem. Finalmente, a fase de metabolismo endógeno ou fase diáuxica, de interpretação bastante polêmica entre os microbiologistas, reflete basicamente o metabolismo endógeno das células remanescentes.

Os trabalhos na área de microcalorimetria biológica, principalmente na fermentação, determinam principalmente a velocidade de produção de calor que é proporcional ao incremento do crescimento celular e produção do etanol. Somente a fase exponencial de crescimento corresponde a um estado termodinâmico com valores específicos constantes, como velocidade de produção de calor, velocidade específica de crescimento, aumento na concentração de metabólitos, aumento do número de células ou velocidade de catabolismo. As outras fases do termograma são períodos de transição de um estado para outro com parâmetros mudando rapidamente. Desta maneira, questões interessantes de transição de fase na termodinâmica de processos irreversíveis podem ser estudados em culturas de microrganismos ${ }^{27}$. Experimentos de crescimento de microrganismos em calorímetros podem ser usados como uma ferramenta analítica quantitativa. Sem quantificar o valor da produção de calor, a análise do termograma pode fornecer informações importantes, como a indicação do crescimento em diferentes vias metabólicas, diferentes situações metabólicas na cultura e na conveniência ou não de se usar um composto químico como substrato. A combinação destas condições pode ser usada como uma "impressão digital" para microrganismos a 
partir de seus termogramas, ou avaliar a aplicabilidade de diferentes linhagens de células na fermentação alcoólica.

Embora os microcalorímetros de fluxo atuais operem com uma sensibilidade máxima de $1 \mu \mathrm{W}^{24,25}$ isto é, um fluxo de calor dq/dt de $1 \mu \mathrm{J} . \mathrm{s}^{-1}$, eles estão limitados pela concentração de microrganismos. Considerando uma taxa máxima de produção de calor de $10^{-11} \mathrm{~W}$ célula ${ }^{-1} \mathrm{~mL}^{-1}$, pelo menos concentrações de $10^{5}$ células $\mathrm{mL}^{-1}$ são necessárias para se ter um sinal significativo. Desta maneira, culturas com concentrações celulares superiores a $10^{5}$ células $\mathrm{mL}^{-1}$ podem ser investigadas. A tabela 1 mostra a comparação da microcalorimetria de fluxo com outras técnicas e suas vantagens e desvantagens ${ }^{22}$.

A resposta de uma cultura de células na mudança de parâmetros tais como composição, natureza da fonte de carbono, tampão, adição de sais, $\mathrm{pH}$, nível de oxigênio dissolvido, quantidade de microrganismos, amino ácidos, vitaminas, contaminação com metais pesados, etc. causam variações mensuráveis na curva dq/dt em função do tempo ${ }^{22}$.

Este trabalho descreve alguns resultados com respeito ao uso da microcalorimetria no monitoramento em tempo real da fermentação alcoólica e a avaliação de diferentes fontes de carbono (sacarose, glicose, frutose, manose, maltose, galactose, melaço, mel e cana de açúcar) no processo fermentativo, utilizando um meio definido e cultura de levedura armazenada em nitrogênio líquido, combinando no laboratório um microfermentador de $50 \mathrm{~mL}$ "on line" com um microcalorímetro de fluxo.

\section{MATERIAIS E MÉTODOS}

O processo fermentativo foi estudado para cada carboidrato, utilizando S. cerevisiae (NCYC-239). Todos os carboidratos utilizados são p.a. da marca BDH (British Drug House). O mel e o melaço utilizados são de marca Super Bom e o mosto de cana de açúcar foi preparado a partir do liofilizado do caldo de cana.

Saccharomyces cerevisiae NCYC-239 foi crescida em frascos de $250 \mathrm{~mL}$ contendo $40 \mathrm{~mL}$ do meio de composição (g. $\left.\mathrm{L}^{-1}\right)$ : $\left(\mathrm{NH}_{4}\right)_{2} \mathrm{SO}_{4}, 2,5 ; \quad\left(\mathrm{NH}_{4}\right)_{2} \mathrm{HPO}_{4}, 2,5 ; \quad \mathrm{MgSO}_{4} .7 \mathrm{H}_{2} \mathrm{O}, 2,0$; $\mathrm{CaCl}_{2} .2 \mathrm{H}_{2} \mathrm{O}, 2,0$; solução de traços de elementos, 0,5 mL.L ${ }^{-1}$; extrato de levedura, 4,0; fonte de carbono, 2,5. A solução de traços de elementos foi de composição $\left(\right.$ g.L $\left.\mathrm{L}^{-1}\right)$ : EDTA, 50; $\mathrm{ZnSO}_{4} \cdot \mathrm{H}_{2} \mathrm{O}, 22,0 ; \mathrm{CaCl}_{2} \cdot 6 \mathrm{H}_{2} \mathrm{O}, 5,5 ; \mathrm{MnCl}_{2} \cdot 4 \mathrm{H}_{2} \mathrm{O}, 5,0$; $\mathrm{FeSO}_{4} \cdot 6 \mathrm{H}_{2} \mathrm{O}, 5,0 ;\left(\mathrm{NH}_{4}\right)_{6} \mathrm{Mo}_{7} \mathrm{O}_{24} .4 \mathrm{H}_{2} \mathrm{O}, 1,1 ; \mathrm{CuSO}_{4} .5 \mathrm{H}_{2} \mathrm{O}, 1,6$; $\mathrm{CoCl}_{2} \cdot 6 \mathrm{H}_{2} \mathrm{O}, 1,6$. Todas as soluções e os materiais utilizados para o preparo da cultura de microrganismos foram esterilizados em autoclave a $121^{\circ} \mathrm{C}$ e $2 \mathrm{~atm}$ por 30 minutos. Quarenta frascos foram inoculados com $0,8 \mathrm{~mL}$ da cultura e incubados à $37^{\circ} \mathrm{C}$ num agitador rotatório Gallenkamp à $220 \mathrm{rpm}$. $\mathrm{O}$ crescimento foi acompanhado por medidas de densidade ótica num colorímetro EEL e após 6 horas de incubação a suspensão de células atingiu a densidade ótica equivalente a $1,2 \mathrm{~g}$ de peso seco de células $\mathrm{L}^{-1}$. As células foram reunidas, centrifugadas, lavadas duas vezes com solução de Ringer contendo $10 \% \mathrm{v} / \mathrm{v}$ de dimetilsulfóxido (DMSO) e centrifugadas. Após a última centrifugação, as células foram resuspensas em solução de Ringer contendo $10 \%$ de DMSO e acondicionadas em ampolas de $2 \mathrm{~mL}$ de polipropileno. As ampolas foram encaixadas numa placa fina de isopor perfurada a qual foi utilizada como tampa de um tanque de alumínio contendo nitrogênio líquido e mantida a uma altura de $8 \mathrm{~cm}$ acima da superfície do nitrogênio. Quando a temperatura na ampola controle (munida de um termômetro de líquido) atingiu $-80^{\circ} \mathrm{C}$, as ampolas foram liberadas para imersão em nitrogênio líquido e guardadas em cilindro criogênico ${ }^{28}$. A contagem viável foi feita periodicamente fornecendo $1,3 \times 10^{10}$ células $\mathrm{mL}^{-1}$. Células armazenadas por 6 meses foram recuperadas em $95 \%$.

Os experimentos de monitoramento da fermentação alcoólica foram feitos utilizando um microcalorímetro de fluxo LKB10.700-1. O esquema de funcionamento do microcalorímetro está mostrado na figura 3 . Todos os experimentos de fermentação foram feitos utilizando a mesma concentração de açúcar $\left(2,5 \mathrm{gL}^{-1}\right)$ e o $\mathrm{pH}$ do meio foi mantido no valor 5,0 , utilizando tampão ácido cítrico/citrato de sódio $\left(7,35 / 19,12 \mathrm{gL}^{-1}\right)$. As soluções foram previamente autoclavadas e cuidados especiais foram tomados para que os experimentos sempre ocorressem em condições anaeróbicas. A mistura fermentativa proveniente do microreator (mantida sob agitação magnética constante e dentro de uma jaqueta com circulação de água termostaticamente controlada na temperatura de $33 \pm 1^{\circ} \mathrm{C}$ ) foi bombeada para dentro da cela de fluxo a uma velocidade de $35 \mathrm{mLh}^{-1}$ com o auxílio de uma bomba peristáltica LKB-2132.

O fluxo de calor dq/dt ( $\mu$ Watts) proveniente do processo fermentativo foi detectado pelo par de termopilhas localizadas ao redor da cela de fluxo ${ }^{21}$.

Antes da inoculação e após a estabilização da linha base, uma resistência elétrica contida no interior da cela de fluxo foi utilizada para a calibração elétrica do termograma, tornando

Tabela 1. Comparação da microcalorimetria de fluxo com outras técnicas no estudo da fermentação alcoólica.

\begin{tabular}{|c|c|}
\hline \multicolumn{2}{|c|}{ DESVANTAGENS DE OUTRAS TÉCNICAS EM COMPARAÇÃO COM A MICROCALORIMETRIA: } \\
\hline$\Rightarrow$ Turbidimetria & $\rightarrow$ Baixa sensibilidade, responde lentamente às variações bruscas de energia no metabolismo \\
\hline$\Rightarrow$ Massa celular & $\rightarrow \mathrm{O}$ mesmo para turbidimetria \\
\hline$\Rightarrow$ Produção de ácido & $\begin{array}{l}\rightarrow \text { Diretamente relacionado ao crescimento e metabolismo somente em casos especiais } \\
\text { - culturas aeróbicas. Variável e dependente da disponibilidade de oxigênio }\end{array}$ \\
\hline $\begin{aligned} \Rightarrow & \text { Medida do potencial } \\
& \text { de oxidação e redução }\end{aligned}$ & $\rightarrow$ Mesmo para a produção de ácido \\
\hline $\begin{aligned} \Rightarrow & \text { Teor de oxigênio dissolvido } \\
& \text { (amperometria) }\end{aligned}$ & $\rightarrow$ Rápido mas limitado à culturas aeróbicas com oxigênio em excesso \\
\hline $\begin{aligned} \Rightarrow & \text { Consumo de oxigênio } \\
& \text { (paramagnético) }\end{aligned}$ & $\rightarrow$ Razoavelmente rápido, mas limitado à culturas aeróbicas \\
\hline $\begin{aligned} \Rightarrow & \text { Formação de } \mathrm{CO}_{2} \\
& \text { (infravermelho) }\end{aligned}$ & $\rightarrow$ Variável sobre diferentes condições metábolicas \\
\hline
\end{tabular}

DESVANTAGENS DA MICROCALORIMETRIA

$\Rightarrow$ Presença de bolhas de gás ou aglomeração das células na linha de fluxo.

$\Rightarrow$ Os microcalorímetros não são suficientemente sensíveis à produção de calor a partir de concentração de células da ordem de $10^{4}$ células $/ \mathrm{mL}$. O limite de detecção é $>10^{5}$ células $/ \mathrm{mL}$. 


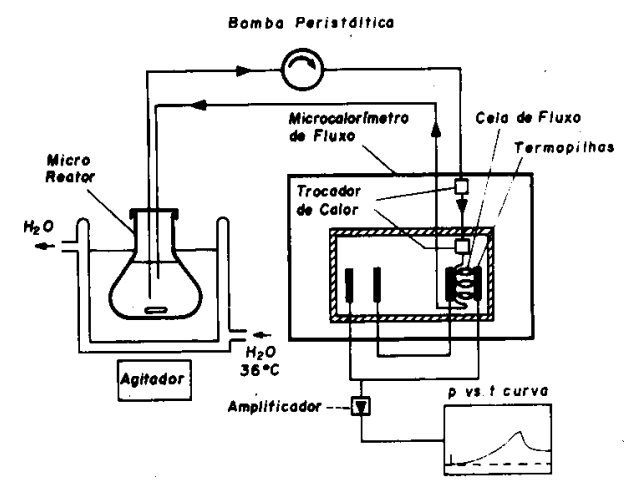

Figura 3. Diagrama do microcalorímetro de fluxo para o monitoramento da fermentação.

assim possível a quantificação do eixo dq/dt do termograma em unidades de $\mu$ Watts.

Calorímetros são normalmente calibrados eletricamente. $\mathrm{O}$ microcalorímetro de fluxo utilizado neste trabalho possui uma unidade de calibração elétrica de precisão, entretanto, nem sempre é fácil simular o efeito térmico biológico com uma resistência elétrica de precisão, de modo que o sensor termopilha reagirá identicamente.

De forma a padronizar os valores das calibrações elétricas para celas calorimétricas, reações químicas são também necessárias. O microcalorímetro foi também calibrado utilizando a reação de protonação do tris(hidroximetilaminometano) ou THAM, recomendada para medidas calorimétricas ${ }^{23,29}$.

A inoculação do microrganismo $(100 \mu \mathrm{L}$ da suspensão de células de $S$. cerevisiae) foi sempre feita imediatamente após o descongelamento da ampola num banho a $36^{\circ} \mathrm{C}$ por 3 minutos seguida de agitação de 20 segundos.

\section{RESULTADOS E DISCUSSÃO}

O monitoramento em tempo real do processo fermentativo de vários carboidratos (sacarose, glicose, frutose, manose, maltose, galactose, melaço, mel e cana de açúcar) foi feito utilizando a combinação de um microcalorímetro de fluxo e um microfermentador "on line", conforme o esquema mostrado na figura 3 . Os termogramas obtidos mostram na sua maioria três fases distintas de produção de calor. Após a inoculação a velocidade de evolução de calor aumenta até um máximo em aproximadamente 8h:50-9h:00 (tempo de exaustão $t_{E}$ ), caindo rapidamente em seguida. A figura 4 mostra os termogramas para o processo fermentativo dos carboidratos glicose, frutose, manose e sacarose, mostrando semelhança nos termogramas da glicose e da fructose. Os termogramas destes carboidratos não apresentam uma fase "lag" longa o que indica que, nas condições do experimento, as células do microrganismo já tem as enzimas e proteínas de transporte prontas para o metabolismo o que corresponde a um tempo de indução muito pequeno. A tabela 2 contém os dados comparativos do processo fermentativo para os açucares glicose, frutose, manose e sacarose obtidos dos termogramas da figura 4. O gráfico da figura 5, contém os dados da tabela 2. Podemos observar do gráfico da figura 5 , que a velocidade do processo fermentativo (coeficiente angular $\mathrm{k}$, obtido pela equação $\ln (\mathrm{dq} / \mathrm{dt})=\ln \mathrm{a}+$ k.t) é a mesma para os açúcares sacarose, frutose e glicose $\left(0,29 \mathrm{~h}^{-1}\right)$, sendo ligeiramente menor para a manose $\left(0,25 \mathrm{~h}^{-1}\right)$. O tempo de exaustão para a glicose e frutose é igual a $8 \mathrm{~h}: 30$ sendo de $9 \mathrm{~h}: 15$ para a manose e de $9 \mathrm{~h}: 40$ para a sacarose. Observa-se, na figura 4, que a velocidade do processo fermentativo para a manose é igual à da glicose e frutose nas 4 primeiras horas do processo. Na fase exponencial esta taxa diminui e consequentemente o tempo de exaustão aumenta. Os termogramas da glicose e frutose são coincidentes.

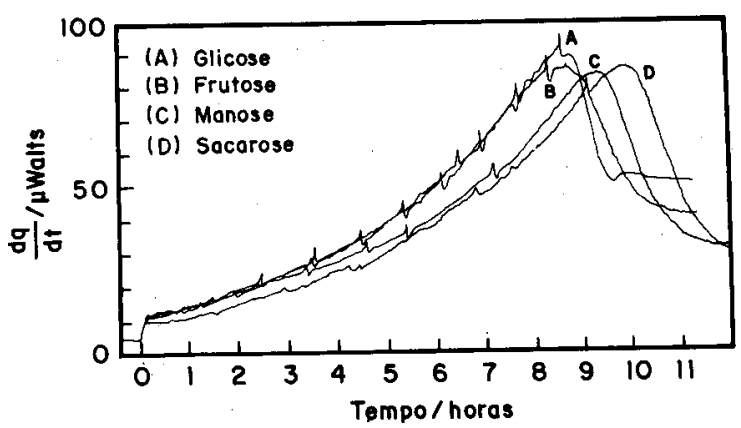

Figura 4. Termograma da fermentação alcoólica utilizando glicose, frutose, manose e sacarose.

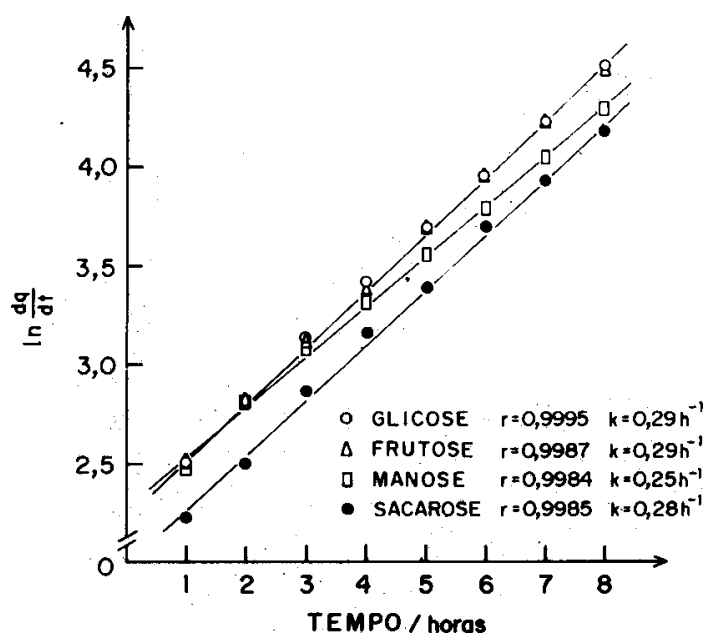

Figura 5. Taxa do processo fermentativo para os açucares glicose, frutose, manose e sacarose.

A figura 6 mostra o termograma do monitoramento do processo fermentativo num meio definido, contendo como fonte de carbono mel de abelha (curva C), mel de abelha desproteinizado por autoclavagem (curva B) em comparação com o termograma de frutose (curva A). Após a autoclavagem e resfriamento da solução de mel, ocorre a precipitação de um material de aspecto gelatinoso devido a desnaturação das proteínas presentes no mel. Observa-se claramente que o termograma da fermentação do mel de abelha desproteinizado (curva B) é coincidente com o da frutose com $\mathrm{t}_{\mathrm{E}}=8 \mathrm{~h}: 30$. O termograma da fermentação do mel de abelha não autoclavado (curva $C$ ), portanto contendo proteínas, apresenta o mesmo tempo de exaustão dos termogramas B e A mas a taxa de crescimento é ligeiramente menor que nos outros dois casos. Além disso, após o tempo de exaustão a diminuição da produção de calor não é tão acentuada como no caso da frutose (curva A) e do mel desproteinizado (curva B) e o termograma apresenta um patamar mais alto, indicando provavelmente que as proteínas são em seguida metabolizadas.

Os picos que aparecem em todos os termogramas são devidos à formação de bolhas de $\mathrm{CO}_{2}$ no interior da cela de fluxo e dos tubos de teflon. Uma vez que as investigações calorimétricas de sistemas heterogêneos, em contraste aos métodos espectrofotométricos, não requerem soluções oticamente transparentes e permite o uso de suspensões de células, tecidos, soluções grosseiras, ou suspensão de compostos bioquímicos, a formação das bolhas de $\mathrm{CO}_{2}$ é inevitável e os ruídos estão relacionados com o efeito da viscosidade e da tensão superficial de cada meio de cultura na formação e despreendimento do $\mathrm{CO}_{2}$. Uma forma de atenuar o ruído no termograma da fermentação devido a evolução de gás seria utilizar no microcalorímetro uma 
Tabela 2. Dados de produção de calor para os açúcares glicose, frutose, manose e sacarose.

\begin{tabular}{|c|c|c|c|c|c|c|c|c|}
\hline \multirow{2}{*}{$\begin{array}{l}\text { Tempo } \\
\text { Horas }\end{array}$} & \multicolumn{2}{|c|}{ Glicose } & \multicolumn{2}{|c|}{ Frutose } & \multicolumn{2}{|c|}{ Manose } & \multicolumn{2}{|c|}{ Sacarose } \\
\hline & $\frac{\mathrm{dq}}{\mathrm{dt}} / \mu \mathrm{Watts}$ & $\ln \frac{\mathrm{dq}}{\mathrm{dt}}$ & $\frac{\mathrm{dq}}{\mathrm{dt}} / \mu \mathrm{Watts}$ & $\ln \frac{\mathrm{dq}}{\mathrm{dt}}$ & $\frac{\mathrm{dq}}{\mathrm{dt}} / \mu \mathrm{Watts}$ & $\ln \frac{\mathrm{dq}}{\mathrm{dt}}$ & $\frac{\mathrm{dq}}{\mathrm{dt}} / \mu \mathrm{Watts}$ & $\ln \frac{\mathrm{dq}}{\mathrm{dt}}$ \\
\hline 1 & 12,3 & 2,50 & 11,4 & 2,43 & 11,8 & 2,46 & 9,3 & 2,23 \\
\hline 2 & 16,7 & 2,81 & 16,2 & 2,78 & 16,7 & 2,81 & 12,3 & 2,50 \\
\hline 3 & 23,2 & 3,14 & 22,8 & 3,12 & 21,8 & 3,08 & 17,5 & 2,86 \\
\hline 4 & 30,7 & 3,42 & 29,8 & 3,39 & 28,1 & 3,33 & 23,7 & 3,16 \\
\hline 5 & 40,4 & 3,69 & 40,3 & 3,69 & 35,5 & 3,56 & 29,8 & 3,39 \\
\hline 6 & 52,6 & 3,96 & 53,1 & 3,97 & 44,7 & 3,79 & 40,4 & 3,69 \\
\hline 7 & 70,2 & 4,25 & 70,2 & 4,25 & 57,5 & 4,05 & 51,8 & 3,94 \\
\hline 8 & 92,1 & 4,52 & 89,5 & 4,49 & 73,7 & 4,30 & 65,8 & 4,18 \\
\hline
\end{tabular}

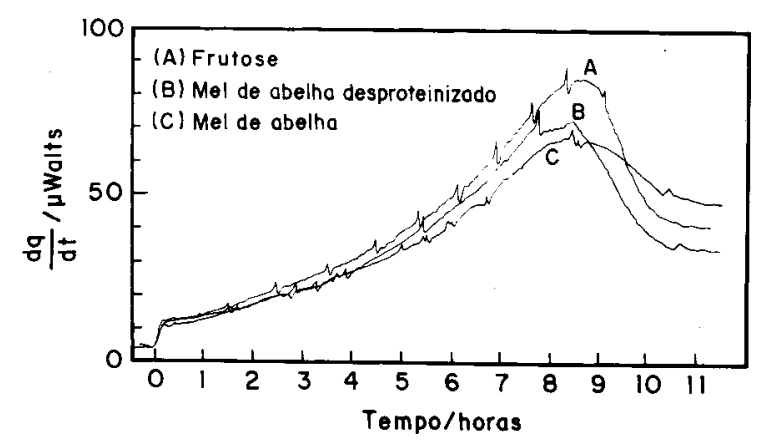

Figura 6. Termograma da fermentação alcoólica utilizando mel de abelha natural e desproteinizado em comparação com a frutose.

cela do tipo batelada, o que inviabilizaria o monitoramento do processo fermentativo "on line".

A evolução da formação de bolhas de $\mathrm{CO}_{2}$ é claramente vista na figura 7 , que é o monitoramento da fermentação de meio de cultura preparado a partir do liofilizado do caldo de cana. Após o tempo de exaustão de $9 \mathrm{~h}: 30$, a formação de $\mathrm{CO}_{2}$ cessa e o ruído é decorrente da quantidade de $\mathrm{CO}_{2}$ remanescente dissolvido no meio de cultura e também de bolhas de $\mathrm{CO}_{2}$ que estavam na linha do sistema de fluxo antes de entrar na cela.

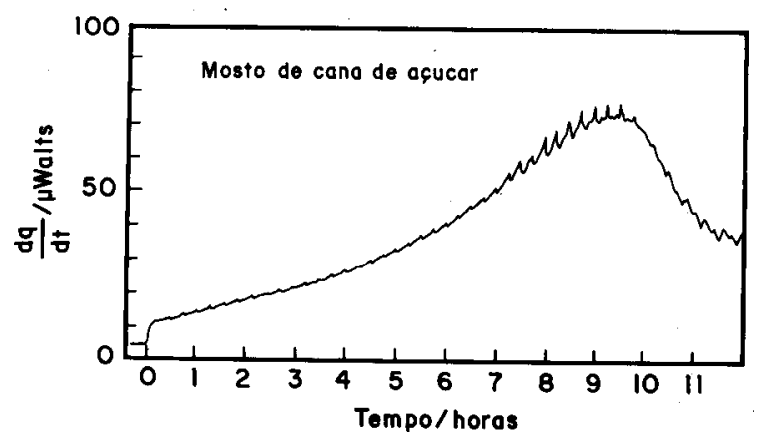

Figura 7. Termograma da fermentação alcoólica utilizando cana de açucar.

É importante lembrar nesta oportunidade que no processo fermentativo da produção industrial do álcool combustível, utilizando a cana de açúcar, a concentração da fonte de carbono é de 18 Brix $=180$ g.L . $^{-1}$, portanto, cerca de 70 vezes mais concentrado que nas condições utilizadas neste trabalho. Utilizamos também neste trabalho como fonte de carbono o melaço e o termograma do processo fermentativo está mostrado na figura $8 \operatorname{com~t}_{\mathrm{E}}=8 \mathrm{~h}: 00$.

O processo fermentativo utilizando a maltose como fonte de carbono, figura 9, é muito lento, comparado com os outros açúcares sacarose, glicose, frutose e manose da figura 4 . Neste

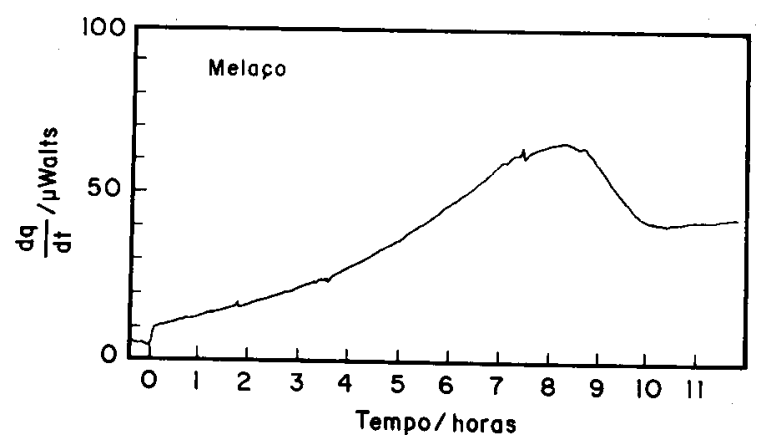

Figura 8. Termograma da fermentação alcoólica utilizando melaço.

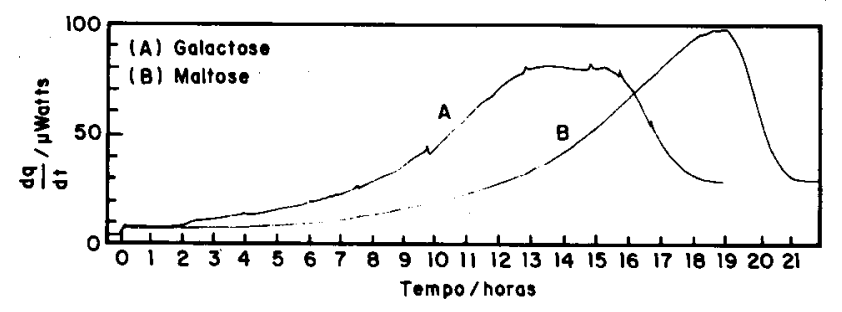

Figura 9. Termogramas da fermentação alcoólica utilizando galactose e maltose.

caso o tempo de exaustão é de 18 a 19 horas, apresentando também uma fase "lag" e de aceleração bem definida e longa. $\mathrm{O}$ mesmo comportamento é também observado quando a fonte de carbono utilizada no processo fermentativo é o açúcar galactose, para o qual o tempo de exaustão é de 13 a 15 horas. Em ambos os casos, o tempo necessário para atingir a fase exponencial é da ordem de 10 horas indicando que tanto a maltose quanto a galactose não são prontamente utilizadas pela $S$. cerevisiae como é o caso dos outros açúcares. No processo fermentativo da maltose e galactose as células demoram para produzir todas as enzimas e proteínas de transporte necessárias para o metabolismo destes açúcares, aumentando portanto o tempo de indução.

Neste trabalho foi possível também verificar que a microcalorimetria de fluxo serve para detectar a ordem temporal da sucessão metabólica dos açúcares. Quando existe mais do que uma fonte de carbono no meio de cultura, o microorganismo exerce a sua capacidade de seletividade metabolizando em primeiro lugar o açúcar que apresenta o menor tempo de indução (favorecimento cinético e termodinâmico) e o termograma apresenta um crescimento bifásico também conhecido como diauxismo. Um bom exemplo de diauxismo é mostrado no termograma do processo fermentativo da mistura de açúcares glicose + maltose, (Figura 10) e glicose + galactose, (Figura 11). Em ambos os casos os meios de cultura foram preparados utilizando concentrações de açucares de 1,5 g.L $\mathrm{L}^{-1}$, totalizando a concentração de fonte de carbono 3,0 g. $\mathrm{L}^{-1}$. Observa-se na figura 10 que após o 


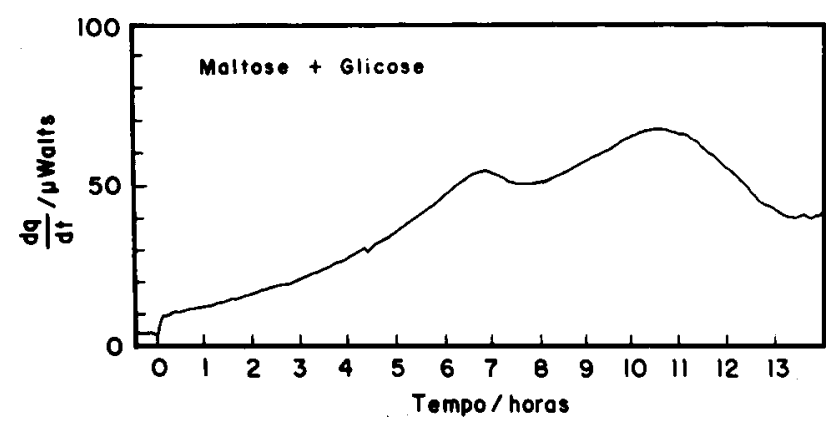

Figura 10. Termograma da fermentação alcoólica utilizando a mistura glicose + maltose.

consumo da glicose com $\mathrm{t}_{\mathrm{E}}=7 \mathrm{~h}: 00$ ocorre o consumo da maltose com $t_{E}=11 \mathrm{~h}: 00$ e o termograma tem um aspecto bifásico, apresentando dois máximos de produção de calor consecutivos na fermentação anaeróbica da mistura glicose + maltose, indicando que a glicose é metabolizada preferencialmente. Entre os dois processos metabólicos há um decrescimento da produção de calor, podemos observar que a seletividade pode ser acompanhada pelo microcalorímetro.

A figura 11 mostra o termograma do processo fermentativo da combinação dos açúcares glicose + galactose. Neste caso, observa-se também que a glicose é metabolizada primeiro, apresentando dois máximos de produção de calor. A aproximidade destes 2 tempos de exaustão em relação ao termograma da mistura maltose + glicose, da figura 10 , é explicada pelo fato do tempo de exaustão da galactose ser menor do que a da maltose.

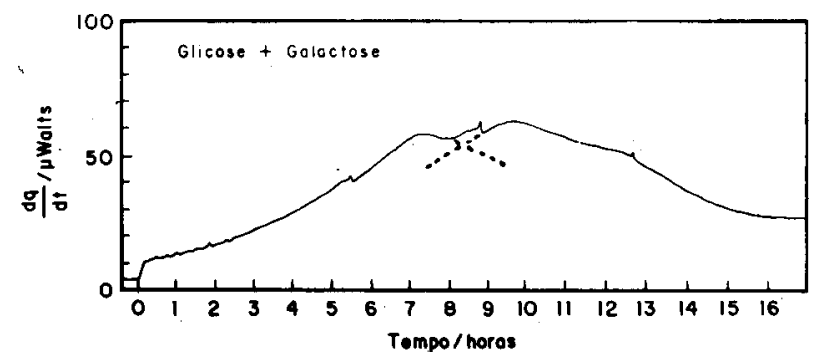

Figura 11. Termograma da fermentação alcoólica utilizando a mistura glicose + galactose.

Mesmo quando o meio de cultura contém apenas um único açúcar, diauxismo pode também se tornar presente. Se o registro do termograma da fermentação de um açúcar é deixado por mais tempo, após a exaustão, (cerca de uma hora após a estabilização da linha base) ocorre novamente um novo máximo de produção de calor. Este tipo de diauxismo é extremamente polêmico entre os microbiologistas, existindo uma respeitável especulação à respeito deste fenômeno. Alguns pesquisadores acreditam que após o esgotamento da glicose um segundo metabolismo aparece, resultante da respiração do etanol ou devido ao metabolismo das reservas do microorganismo (metabolismo endógeno) ou reserva de energia utilizável no ciclo da célula na ausência de nutriente. Outros pesquisadores acreditam que esse tipo de diauxismo aparece quando as células têm que se adaptar a partir da fermentação anaeróbica da glicose para a respiração do etanol ${ }^{22}$.

A armazenagem de reservas energéticas em microrganismos, foi revista por Dawes e Senior ${ }^{30}$. O glicogênio e a trealose de leveduras foram discutidos por Manners ${ }^{31}$, Lillie e Pringle ${ }^{32}$, os quais estudaram o metabolismo da reserva de carboidratos em $S$. cerevisiae e mostraram que o glicogênio e a trealose contribuem com $1 \%$ na fermentação da glicose.

Este comportamento energético é refletido também no crescimento da biomassa, mas sua inclinação é menos pronunciada e informativa. Muitos pesquisadores discutem o fenômeno do metabolismo endógeno levando em consideração a grande vantagem energética da respiração representada pela reação:

$\mathrm{GLICOSE}+6 \mathrm{O}_{2}+38 \mathrm{ADP}+38 \mathrm{P} \rightarrow 6 \mathrm{CO}_{2}+6 \mathrm{H}_{2} \mathrm{O}+38 \mathrm{ATP}$

sobre a fermentação e consideram que o metabolismo endógeno deva ser aeróbico a partir de um ponto de vista de geração de energia.

Foi portanto, possível, estudar a fermentação alcoólica utilizando soluções diluídas de diferentes açucares, demonstrando que a microcalorimetria de fluxo é uma ferramenta sensível para detectar e monitorar em tempo real, o metabolismo (Energia) da fermentação alcoólica, "on line".

O futuro da calorimetria nesta área é auspicioso devido ao desenvolvimento de novas técnicas e o melhoramento da instrumentação para o monitoramento térmico. Com isto será possível fazer um estudo ainda mais detalhado de sistemas celulares, sendo grande o potencial para medidas térmicas em ciências básicas, medicina, farmacologia e toxicologia.

\section{AGRADECIMENTOS}

O autor agradece o Professor Roger Miles do Departamento de Microbiologia, King's College, Universidade de Londres pelas proveitosas discussões sobre o metabolismo fermentativo da $S$. cerevisiae e a cooperação bilateral $\mathrm{CNPq} / \mathrm{British}$ Council.

\section{REFERÊNCIAS}

1. Dubrunfaut, M.; C.r. Séanc. Soc. Biol. 1856, 42, 945.

2. Hemminger, W. e Höhne, G.; In Calorimetry, Fundamentals and Practice, Verlag Chemie, Weinheim 1984.

3. Rubner, M.; Arch. Hyg. 1903, 48, 260.

4. Rubner, M.; Arch. Hyg. 1904, 49, 355.

5. Rubner, M.; Arch. Hyg. 1906, 57, 193.

6. Rubner, M.; Arch. Hyg. 1906, 57, 244.

7. Calvet, E. Prat. H. e Skinner, H. A.; In Recent Progress in Microcalorimetry, Pergamon Press, London 1963.

8. Belaich, J. P.; Senez, J. C. e Murgier, M.; J. Bacteriol. 1968, 951750.

9. Fujita, T., Nunomura, K. Kagami, I e Nishikaura, Y.; J. Gen Appl. Microbiol. 1976, 22, 43.

10. Forrest, W. W.; Methods Microbiol. 1972, 6b, 285.

11. Beezer, A. E.; In Applications of Calorimetry in Life Sciences (Lamprecht, I. e Schaarschmidt, B., eds), de Gruyter, Berlin and New York, 1976.

12. Luong, J. H. T. e Volesky, B.; Adv. Biochem. Eng. Biotechnol. 1983, 28, 1.

13. Calvet, E.; In Experimental Thermochemistry (Skinner, H. A., ed.), Wiley, New York, 1962.

14. Belaich, A. e Belaich, J. P.; J. Bacteriol. 1976, 125, 14.

15. Mou, D-G. e Cooney, C. L.; Biotechnol. Bioeng. 1976, 18, 1371.

16. Wang, H.; Wang, D. I. C. e Cooney, C. L.; Eur. J. Appl. Microbiol. Biotechnol. 1978, 5, 207.

17. Luong, J. H. T.; Yerushalmi, L. e Volesky, B.; Enzyme Microb. Technol. 1983, 5, 291.

18. Erickson, R. e Holme, T.; Biotechnol. Bioeng. Symp. 1973, 4, 581

19. Monk, P. R.; J. Bacteriol. 1978, 135, 373.

20. Ishikawa, Y.; Shoda, M. e Maruyama, H.; Biotechnol. Bioeng. 1981, 23, 2629.

21. Volpe, P. L. O.; Quím. Nova 1993, 16, 49.

22. Beezer, A. E.; In Biological Microcalorimetry, Academic Press, London 1980.

23. Wadsö, I.; In Thermal and Energetic Studies of Cellular Biological Systems (Ed. A. M. James) Wright, Bristol 1987, p.34. 
24. Volpe, P. L. O.; Quím. Nova, 1987, 10, 122.

25. Volpe, P. L. O.; Quím. Nova 1988, 11, 435.

26. Interunion Commission on Biothermodynamics, Pure and Appl. Chem. 1982, 54, 671.

27. Forrest, W. W. e Walker D. J.; Nature 1964, 201, 49.

28. Kirsop, B. E. e Snell, J. J.; In Maintenance of Microorganism. Academic Press, New York, 1984.
29. Volpe, P. L. O. e Silva Filho, E. A.; Thermochimica Acta 1995, 257, 59.

30. Dawes, E. A. e Senior, P. J.; Adv. Microb. Physiol. 1973 10, 135.

31. Manners, D. J.; In The yeast; Ed. A. H. Rose e J. S. Harrison Academic Press, New York, 1971, vol.2, p.418. 32. Lillie, S. H. e Pringle, J. R.; J. Bacteriol. 1980, 143, 1384. 